\title{
Aprender lúdicamente Juego y performance para impulsar la innovación y la creatividad en la Universidad
}

\section{Introducción}

En este trabajo reflejamos una serie de principios básicos de la educación artística que confrontamos con una pedagogía experimental en los estudios de arquitectura. Nuestra metodología se basa en la acción directa sobre la realidad urbana, trabajo de campo e interacción con los demás frente a presupuestos abstractos y respuestas proyectuales basadas en la forma/diseño. Una acción es un proyecto que no tiene como principal objetivo un resultado o la forma final sino la experiencia del hacer, de tener una experiencia vital. Pretendemos de ese modo, la agudización de los sentidos, un acercamiento a lo urbanohumano, el entendimiento del espacio de la ciudad como espacio convivencial. En nuestros talleres desarrollamos propuestas no convencionales de intervención y transformación de la realidad. Estas experiencias luego han de ser comunicadas y socialmente integradas. Son procesos creativos que trasvasan los límites de la disciplina y generan aprendizajes intuitivos, activos y productivos mucho más eficaces.

\section{El aprendizaje corporal}

Una convicción compartida es aceptar que los seres humanos tienen deseos básicos de autonomía e inventiva, de autodefinición o autopoiesis. Los procesos para su logro suelen comenzar por una toma de conciencia de una resistencia activa a la educación formal y la decisión de dedicar esfuerzo a esta resistencia. Luego, iniciado el proceso de autoeducación, nunca se detiene. Las personas adquieren destreza y clarividencia cuando se interesan verdaderamente por lo que están haciendo (por hacer) (Seguí, 2012).

Aprender es la herramienta principal para sobrevivir como individuos y como grupo o comunidad. El ser humano posee inteligencia que es capacidad de descubrir, sopesar y relacionar hechos con el fin de solucionar problemas, anticipar y planear. Para resolver problemas siempre se ha servido de dos estrategias: la invención y construcción de herramientas (útiles y artefactos) especializadas, es decir, la técnica como fundamento de supervivencia y el lenguaje (símbolos que representan estados del mundo). Entre herramientas, lenguaje y pensamiento hay una conexión (Dunbar, 2002).

De Gesture and the Nature of Lenguage (Armstrong-Stokoe-Wilcox, 1995), aprendemos que las percepciones sensoriales combinadas con el movimiento, la acción y la emoción son la base de todo

Revista Iberoamericana de Educación / Revista Ibero-americana de Educação

ISSN: $1681-5653$

n. ${ }^{\circ} 63 / 1-15 / 09 / 13$

Organización de Estados Iberoamericanos para la Educación, la Ciencia y la Cultura (OEI-CAEU)

Organização dos Estados Ibero-americanos para a Educação, a Ciência e a Cultura (OEI-CAEU) 
aprendizaje. El movimiento posibilita todas las categorías perceptuales. Movimiento y sensación se convierten conjuntamente en el antecedente del significado. No es sólo el lenguaje consistente en palabras, sintaxis-semántica sino también el gesto y la acción que organizan los significados. Existe en este sentido, una estrecha relación entre el desarrollo anatómico del ser humano, el movimiento, la percepción, el aprendizaje y la expresión como previamente había estudiado Bell en Essays on the anatomy of expresión (1806).

De estos principios básicos deducimos que las técnicas más eficaces para desarrollar la inteligencia tenderán siempre a la unidad, no al divorcio, de mente y cuerpo. El aprendizaje que es enigmático, el misterio quintaesencial de la vida humana, es fusión de lo físico, cognitivo, emocional y espiritual. La cognición es una realización de todo el 'animal', no de un mecanismo interior a él y al que sirve de vehículo. Por consiguiente, no hay nada semejante a una 'inteligencia' fuera del propio 'animal', como tampoco hay ninguna evolución de la inteligencia que no sea su evolución con sus propias facultades de percepción y acción. La capacidad para imaginar -para soñar- está fuertemente vinculada a la capacidad exclusivamente humana de crear complejidad no sólo con el pensamiento sino con el acto.

Nos dice Nancy (2003, pp.93-94): el aprendizaje es corporal, pertenece a la experiencia sensorial y es del orden de la emoción, palabra que quiere decir puesto en movimiento. La emoción o la conmoción del cuerpo, puesto en movimiento con, implica exposición al afuera, apertura. "El cuerpo es la extensión y la exposición". "El cuerpo es abierto e infinito". Jean-Luc Nancy (2007) en Le Plaisir au dessin, habló del "placer del dibujo", lo que se conoce en otros contextos y en cualquier forma de arte como "el placer del gesto". El placer en cuestión debe ser entendido como el deseo de la forma que será, o más bien que la forma sea "de alguna manera"; el placer movimental de la forma haciéndose.

Entender el cuerpo como un instrumento con el que sentir placer implica un cambio radical en concebir el aprendizaje sobre la base del cuerpo frente a los aprendizajes predominantes reducidos al intelecto y a la visión. El aprendizaje visual hegemónico presupone códigos de entendimiento, y resulta, por eso, impositivo y autoritario. El saber del cuerpo (inconsciente-intuitivol es, sin embargo, productivo de saber original, genérico, madre de todas las artes (Nancy, 2003).

Didi Huberman (2008) nos acerca a la danza como "poesía general de la acción", como exploración de la alteración del cuerpo e interrogación sobre el ser. Estar en movimiento significa "estar fuera de las cosas, formando tiempo y fragmentos configurativos que se desenvuelven en un acto puro de metamorfosis". Estar en movimiento es pasar del estado de "cosa" a ser "acontecimiento". El bailaor pauta sus gestos en la extensión desplegada del cuerpo dentro de la profundidad del espacio que inventa bailando proyectándose en él. "No se puede ser-en-el-mundo sin proyectarse en él". Sin alterar este mundo.

\section{El impulso creativo como centro del aprendizaje en la universidad}

El impulso creativo, profundamente personal, es un elemento fundamental, motor del aprendizaje. Implica probar y explorar ideas, reunir información y tomar decisiones para poder avanzar hacia metas que uno juzga valiosas. El trabajo creativo puede iniciarse en cualquier circunstancia. El detonante puede ser cualquier cosa. No hay objeto ni acción que quede excluido. Los actos creativos surgen del impulso de alterar algo o de alterar un estado interior o de comunicar algo a los demás, capaz de alterar su estado 
interior. Mediante la actividad creativa puede el individuo conocer el mundo y definir su propio lugar en él. Todos los que desean hacerlo pueden hacerlo sin excepción. Pero una curiosidad innata paralizada o un aislamiento miserable pueden sofocar la creatividad (Seguí, 2012).

Una forma común para activar el trabajo heurístico y creador es generar las condiciones que desencadenan una actividad lúdica. Aprender jugando implica unir la actividad al placer. Pero el juego siendo una actividad libre y voluntaria, sabemos, conlleva disciplina y esfuerzo; no es arbitrario, se desarrolla en un determinado espacio y tiempo según reglas libremente acordadas pero imperantes que acompañan un especial sentimiento de tensión (Huizinga, 1938). Las condiciones físicas y el estado emocional en que se produce son esenciales. Incidir y alterar las condiciones físicas y el estado emocional es, entonces, clave para que un proceso creativo se inicie.

Pero la emoción como afirma Zygbmund Baumann (2011, p.44) "si es apta para destruir resulta especialmente inepta para construir nada". Por eso, es esencial propiciar experiencias constructivas que sean conmovedoras y nos hagan reflexionar (hablar) sobre la arquitectura, el mundo y nosotros mismos. La educación artística ha de entenderse como el modo más natural de integrar cabalmente la percepción, el sentimiento, la reflexión y la expresión. Su materia es la totalidad de la experiencia.

Para provocar este tipo de experiencias, desencadenamos procesos que salen fuera de la disciplina estrictamente académica. Son experiencias vitales, interactivas, trabajos de campo, prácticas dentro de una realidad latente; iniciativas y juegos que emanan del puro deseo. Se inician a través de las propuestas que los propios estudiantes formulan. Más o menos vagas, emanan de su vitalidad y libertad. Estas iniciativas desencadenan proyectos con el apoyo del profesor, a través del diálogo, con una cierta disciplina pero no autoridad. Cualquier propuesta, lo más disparatada que puede parecer, puede fructificar en un proyecto que lleve a cada estudiante a una particular forma de responder a una determinada situación. Se trata de aprender por sí mismo y de sí mismo, a ser uno mismo y a descubrir su individualidad. El papel del profesor es apoyar, reforzar, cualquier iniciativa potenciando la seguridad y la confianza del alumno a sí mismo, ayudándole a buscar información pero jamás imponiéndole una visión.

Estos procesos creativos empiezan en las aulas y se prolongan fuera de las aulas en contacto con los otros. Son aprendizajes colaborativos entre los propios compañeros de curso pero pretendemos que se mezclen y aprendan también de los demás, que se abran al mundo. Estamos convencidos que la innovación educativa en la Universidad tiene que proceder de los incesantes cambios que ocurren en la sociedad y en nuestro campo particular, de las nuevas demandas de habitabilidad y convivencia. Nuestras referencias proceden del mundo del arte y el pensamiento en torno al arte. Son, sin duda, aprendizajes heterodoxos basados en la pura experimentación, la utilización de léxicos anticonvencionales en la disciplina. Dispuestos constantemente a lanzarnos al vacío, nos aproximamos, a veces, a actitudes líricamente contraculturales y deliberadamente desarraigadas. Como diría Levi-Strauss (1984), bordeando la vulneración y la destrucción de los códigos y generando situaciones de "ambigüedad" y "extrañamiento". Este hacer (acción) necesita luego compensarse con relatos que crean sentidos (lenguaje).

La enseñanza supone asumir el desconocimiento como dato intrinseco del problema. Por eso no enseñamos sólo lo que sabemos del mundo, sino cómo captar sus posibilidades ocultas. No queremos llenar las cabezas de los estudiantes de nuestras obsesiones, sino básicamente poner en duda las certezas para que aparezca el deseo de aprender más (Rancière, 2003). 
La primera regla del juego es, precisamente, romper con las formas de operatividad normativa, rutinas y procesos comprobados y repetitivos. Los procesos se conducen a la creación de situaciones nuevas (extrañantes), a través de acciones que transforman el entorno, nuestra percepción de este entorno y de los otros poniendo en crisis los códigos (convencionales) del entendimiento y recurriendo a las palabras de una manera distinta para describirlas. Una cosa que siempre habíamos visto y conocido es alterada, percibida de una manera nueva, introducida en un contexto diferente. Se aprende a mirar de otra manera (extrañamiento) y como es natural también haciendo descripciones nuevas.

El performance es para nosotros una modalidad creativa y comunicativa que consigue aumentar la dificultad y la duración de la percepción creando situaciones u objetos como si fueran por primera vez; como si no existieran fórmulas y métodos para ello y donde la finalidad de la acción no es acercar a nuestra comprensión la significación de la que es vínculo sino crear una percepción particular de la situación o el objeto. Las obras, instalaciones y situaciones como resultados de las acciones no son más que un residuo físico, un resto de algo que es mucho más importante y esencial. Lo esencial en el arte, como se había suscitado y permanecido latente desde los situacionistas (Debord, 1957) es la actividad artística.

\section{El performance y lo real}

Los procesos heurísticos y creativos que ponemos en marcha en nuestros talleres bordean conscientemente un "grado cero de la arquitectura". Una "reducción a cero" es una negativa frente a los códigos dominantes, lo que sería responder a todos los problemas básicos como si fuéramos a construir por primera vez o la primera casa de la historia. Nos acercamos de alguna manera a la fisión semántica o los procesos de descontextualización. Las situaciones creadas son escenarios de historias vividas e historias narrables. Aunque evidentemente no se identifican totalmente con lo arquitectónico, nos suministran indicaciones válidas para una pedagogía de la creatividad y la innovación donde el cuerpo (la acción) ocupa el primer lugar pero el cuerpo envuelto en palabras. La narración da sentido a los actos porque cuando se hace no se piensa. Cuando se piensa no se hace. Porque no se puede saber lo que uno quiere hacer de antemano a no ser algo preconcebido o convencional. Proyectar una situación nueva, algo que no existe (arquitectura), no es simplemente reunir datos y aplicar conocimientos. La implicación, el compromiso personal es lo más importante en este tipo de acciones.

Como un importante sector del arte, en las últimas décadas, la educación artistica tiene la tarea de proporcionar una percepción más fuerte e intensa de la realidad. "Esta experiencia artística se ha configurado como una verdadera y auténtica irrupción de lo real en el mundo rarefacto y, altamente, simbólico del arte" (Perniola, 2002, 17). La separación entre el arte y lo real parece desplomarse definitivamente.

"Ha nacido una especie de 'realismo psicótico' que anula cualquier mediación. El arte pierde su distancia respecto a la realidad y adquiere una fisicidad y una materialidad que nunca había poseído antes; la música es sonido, el teatro es acción, el arte figurativo tiene una consistencia a la vez visual, táctil y conceptual... Ya no son imitaciones de la realidad, sino realidades tout court no mediadas ya por la experiencia estética; son extensiones de las facultades humanas que, sin embargo, ya no deben rendir cuentas al sujeto porque éste se ha disuelto completamente en una exterioridad radical" (Perniola, 2002, p.41). 
Recordando a Oteiza $\left(2009,6^{\text {a }}\right)$ cuando decía: "el artista ya no es necesario dentro del arte sino desde la vida, para continuar desde la vida", habría de reconducir la experiencia artística dentro de la realidad, la cotidianidad y la convivencia. La tendencia contraria nos lleva hacia la separación, el alejamiento de la experiencia artistica de la vida real. En la actualidad, esta tendencia tiene un potente aliado en los medios de comunicación de masas, la idea del espectáculo de masas, la comercialización del tiempo libre y la arquitectura como espectáculo. Como este importante sector del arte, en las últimas décadas, la arquitectura tiene que abandonar el mundo simbólico y acercarse a la vida cotidiana (De Certeau, 1999). Entender los procesos configurativos la arquitectura como un arte performativo, como acción sobre lo real tiene hoy una doble consecuencia.

"Lo real que irrumpe y sacude el mundo del arte no es sólo aquello arraigado en la dimensión antropológica, sino también y, sobre todo, aquello más bien ajeno e inquietante de los dispositivos tecnológicos y económicos. El lugar decisivo de este realismo extremo se convierte, en el encuentro entre el ser humano y la máquina, entre lo orgánico y lo inorgánico, entre lo natural y lo artificial, entre la pulsión y la electrónica, entre la persona y la mercancía. El núcleo duro de lo real con el que estamos obligados a enfrentarnos es el cyborg, la cobaya tecnológica, la moneda viva, el capital humano. La noción de virtual, que a primera vista nos parecía unida a la tendencia espectacular y desrealizante, asume un significado opuesto: el cuerpo virtual, poseído y diseminado en las redes, se convierte en otro objeto, extremadamente inquietante, irreducible a la dimensión imaginaria y simbólica" (Perniola, 2002, pág.18-19).

El proyectar como acción-ejecución nos lleva también hacía los medios tecnológicos como medios estratégicos de una ilimitada operatividad y una inmensa capacidad para la interacción, el análisis y la interpretación de un contexto. Pues, posibilitan nuevas descripciones así como nuevos modos de experimentar el entorno (la ciudad) en un encuentro lúdico entre el espacio físico y el espacio virtual. Los modos de interacción entre el espacio físico y el virtual nos proporcionan nuevos datos y nuevos modos de interpretarlos, al mismo tiempo que nuevos modos de relacionarnos en el espacio. Habitamos y actuamos en espacios híbridos entre lo real (que es in situ y virtuall y lo virtual (las imágenes y las palabras). El uso de las nuevas herramientas (digitales y telemáticas) amplía nuestra capacidad proyectual. Nuestras propuestas pueden ahora dar razón del cambio histórico (de las diferencias en la concepción del espaciotiempo vivido) y hacer una crítica constructiva de lo social.

Uno de los principales objetivos de la educación universitaria es crear una conciencia del entorno. El mejor modo de hacerlo es la intuición capaz de correlacionar imágenes y conceptos, sensaciones y reflexiones. El conocimiento instintivo nos agarra a la realidad, a las condiciones vigentes que organizan la sociedad. Y como la civilización contemporánea propicia hábitos y proporciona medios de integración, facilita una toma de posición que equivale a tomar consciencia. Consecuentemente el posicionamiento subjetivo implicaría un comportamiento libre y por tanto crítico frente a las cosas (Read, 1982).

\section{Fundamentos de la innovación educativa en el performance}

Estudios teóricos del performance como los de Goffman (1959) observan el performance como una metáfora de la acción humana y como un paradigma analítico que propone nuevos modelos teóricos que son centrales, no accesorios, del acontecer social, político y cultural. El performance es como una esponja que absorbe todo lo que encuentra a su paso: la lingüistica, las teorías de la comunicación y de la conducta, la antropología, el arte, los estudios escénicos, los estudios de género...hasta la técnica constructiva y los 
medios tecnológicos. Es mutante gracias a su asombrosa capacidad de transformación en una hueste de significados escurridizos y es nómada de una disciplina a otra y también de un lugar a otro.

Cualquier tipo de actividad humana puede estudiarse como performance; abarca desde el rito, el juego pasando por el deporte, espectáculos populares, artes escénicas, eventos sociales, actuaciones en roles de clase y género, la vida cotidiana, los medios masivos e internet (Schechner, 2002 y 2003). Es factible incluir también el estudio de objetos en su aspecto performativo como los juguetes (Weisz, 1986), las instalaciones y otros. Su desplazamiento transfronterizo, permite estudiar un fenómeno cualquiera como performance, en sus aspectos de teatralidad o performatividad (Taylor, 2001). Pero aquí lo que interesa básicamente es cómo actúa educando, intensificando los procesos perceptivos y facilitando aprendizajes en habilidades inventivas e imaginativas a la vez que enfoca valores y despliega estrategias para subvertir lo establecido.

El performance, efectivamente, permite la construcción y el análisis de situaciones diluyendo las barreras entre la representación y la vida (Turner, 1998). Como proceso de aprendizaje facilita ampliar nuestra percepción de una realidad cada vez más compleja, más interdisciplinar y transversal. Lo híbrido, lo fragmentario, lo intersticial, lo marginal, lo agonístico, lo lúdico... nos atrae frente a los mitos centrales, las convenciones, los conocimientos academicistas... Asi nuestras acciones se oponen a los fines predeterminados, al objeto terminado a favor del propio proceso. Nos oponemos a los valores universales, a las esencias y también a la autoría. El sujeto no expresa nada. Son los hechos que expresan el sujeto. La premisa fundamental es el sujeto descentrado, el cuerpo extenso, la acción que resiste a los actos (Agamben, 1998).

Se trata de una manera alternativa de saber, de una epistemología del cuerpo y de la acción que involucra los sentidos, los deseos y las limitaciones físicas. El performance implica un embodied knowledge. Se trata de un conocimiento donde implícitamente están el estudio antropológico del comportamiento y el lingüistico así como el construccionismo social. El performance se convierte en arte y a partir de los 70 s en acción social que propicia la articulación de identidades minoritarias, disidentes y subalternas. Se usa en resistencia a los poderes hegemónicos mediante estrategias de parodia, ironía, carnavalismo y trasgresión. El performance crea nuevos espacios, articula nuevas epistemologías identitarias. Al hacer emerger una 'conciencia oposicional' o contestataria, enarbola 'políticas de la diferencia' y 'políticas de coalición'. Es para nosotros clave para contrarrestar el nihilismo posmodernista, el neoliberalismo y la globalización económica que saturan de contenidos nuestra tarea proyectual.

El situacionismo fue un movimiento que ha proporcionado las claves para entender el comportamiento performativo. Para los situacionistas, el ser humano solamente podría vivir una vida a su medida si él mismo la creara. Su rama utópica (Constant, 1974) visionaba un mundo construido como una cadencia de situaciones lúdicas. Constant inventó New Babylon, un mundo que tendría lugar cuando la lucha por la existencia no sería más que un recuerdo y el individuo podría disponer libremente de su vida. Lejos de permanecer pasivo ante el mundo contentado sólo con adaptarse, de una manera o de otra, a las circunstancias externas, desearía crear otro mundo en el que todos consigan su propia libertad. Para poder crear uno su propia vida, haría falta que creara antes este mundo. Podría, entonces, con total libertad, dar a su espacio existencial la forma de sus deseos. La "deriva" situacionista hacia el terreno político, propició la disolución del hecho artístico en el campo de la acción social, la transformación de la obra en acto y un radical cambio en el funcionamiento discursivo de la obra en el campo de la estética. 
Jürgen Habermas, autor de una monumental Teoría de la acción comunicativa, sitúa el performance en un cuarto ámbito, más allá de la acción instrumental, la acción ética y la acción estética -las tres formas tradicionales de la acción-, en el lugar de la acción propiamente comunicativa. La acción instrumental se dirige a la consecución de un fin; la acción ética, al hacer regulado por normas. La acción estética es la actuación dramática. El autor que se autorrepresenta implica dos nociones clave que son para Habermas las de "encounter" $y$ "performance". El hacer dramático constituye una interacción social que asume una connotación estratégica (Habermas, 1989, 185).

Toda interacción social, las acciones más banales, los gestos más mecánicos, los pensamientos más grises se pueden contemplar de una manera diferente, pueden convertirse en una 'acción poética'. Sólo hace falta darles la vuelta para descubrir la esencia poética de la sencillez. No hay que ser uno rebuscado para realizar una 'acción poética'. Esa es una acción que interpela la reacción de los asistentes, los epata de algún modo; se revive en grupo (feedback). Una acción que conmueve puede ser también transgresora y perturbadora pero sin buscar la provocación gratuita. No es teatro. Es un atreverse a vivir con los cinco sentidos y con cierta desmesura, siempre con curiosidad y sensibilidad hacía lo que nos rodea. El performance es el juego de acoger datos del entorno y transformarlos conscientemente. Es el juego de deformar la realidad como un espejo de feria o convertirla en una realidad poética. Es provocar un humor distinto, una reacción, una participación.

La acción (expresada con la palabra inglesa happening que significa evento, ocurrencia, suceso), no se focaliza en objetos, en la obra, sino en el evento donde los sujetos dejen de ser sujetos pasivos y, con su actividad, alcanzan una liberación a través de la expresión emotiva y la representación colectiva. La participación, la interacción, la improvisación o la imprevisibilidad de un evento, la espontaneidad y su carácter efímero, su desarrollo en lugares públicos como un gesto de sorpresa o irrupción en la cotidianeidad son todos ellos ingredientes de lo social magmático, líquido en constante transformación. Lo urbano configurándose como espacio vital por la acción de los seres vivos móviles y movilizados por la acción (Delgado, 2007, Lefebvre, 1969) constituye una visión diferente de lo estable consolidado, los edificios, los monumentos.... como se piensa habitualmente la ciudad. Por eso, aprendemos antes que proyectar edificios a proyectar espacios para la vida.

Como fin último de este aprendizaje no es tanto la generación de conocimientos ni la producción de las mejores obras sino una cierta madurez y sabiduría que nos hace más humanos. En este sentido, concebimos la educación en la Universidad no como suma de competencias en materias y especializaciones que responden sólo a la acumulación de un proceso histórico. La educación debe ser, ante todo, innovadora e inductora de investigación. Y ha de ser humanista, integradora, generadora de compensaciones y equilibrios, y propiciadora de felicidad. Ha de promover procesos sencillos y diáfanos que motiven a los estudiantes, que activen su sensibilidad por el entorno y las iniciativas de transformarlo. Ha de promover prácticas educativas de validación empírica en campos fértiles de creatividad donde el arte tiene la capacidad de vivificar lo concreto. 


\section{Aprendizaje basado en proyectos de espacios vitales}

Sí la investigación del performance constituye un campo emergente, transdisciplinario, intercultural y transfronterizo todavía es marginal en el mundo académico. En las enseñanzas de la iniciación proyectual en arquitectura, podemos considerar el performance como anticipación de un estado nuevo: el "grado cero de la arquitectura" que comienza con un estado "actuado" y luego "hablado" o "narrado". Si el cometido de la arquitectura es la configuración del espacio, el espacio no es una magnitud fija e inmóvil separada de las acciones y dinámicas puestas en marcha. El espacio no es el receptáculo de nuestra acción sino que surge con nuestra acción. Entendemos el espacio como dimensión dinámica de los actores que más que actuar en un espacio, crean y desarrollan un espacio cuando actúan, en virtud de su actuación. Eso es pensar el espacio como el proceso mismo y no como el resultado de un proceso. Es entender lo arquitectónico como experiencia vital, como la espacialidad envolvente de las vivencias humanas.

El espacio vivencial es el habitar extremo, nómada, provisional... es la ciudad como posibilidad de situaciones y eventos interactivos, la "deriva" situacionista como investigación de la realidad. Cada acción imbuida en la realidad táctil nos parece experiencia casi-casi inusual en un mundo dominado por lo visual y lo virtual (De Certeau, 1999). A través del performance, podemos aislar aspectos de la realidad, obtener recursos que permitan comprenderla y transformarla según criterios realistas pero no convencionales. Porque vivimos como jugamos, jugamos como vivimos. Jugar, al fin y al cabo, no es sólo alterar el estado natural y la secuencia lógica de las cosas para entrar en un espacio-tiempo diferente. Es más. En efecto, a través del jugar, pueden transmitirse todos aquellos valores ocultos y a veces hasta altamente tóxicos que reproducen modelos para perpetuar repartos asimétricos de poder y diferencias asumidas como naturales entre géneros, razas, clases y grupos humanos (Acaso-Nuere, 2005). Y claro, saltar al otro lado siempre ha sido tentador pero peligroso, sobre todo para el sistema de control de padres, educadores, políticos y sociedad en general.

En nuestros talleres de iniciación en la proyectación arquitectónica, se construyen actos antes que producir dibujos u objetos. Son prácticas abiertas, sin contar con un fundamento cierto para hacerlas, sin apoyarse en armazones teóricos concluyentes. Se hacen suposiciones, se comercia y trafica. No se comprueban resultados, no se demuestran tesis. Se producen contradicciones, se muestran incongruencias. Pero no se trabaja sobre lo etéreo, se reflexiona con el movimiento. Actuar antes que reflexionar implica llegar a la pura proyectación, al hecho abstracto de crear, antes de etiquetarla con el nombre de una asignatura académica (Amann, 2011). Son ejercicios extrañantes que requieren liberar el imaginario de tareas útiles-convencionales, dejando fluir la imaginación entre varias disoluciones arquitectónicas: las dimensiones, la escala, el espacio, el tiempo, los aconteceres, las justificaciones cotidianas, las utilidades y la coherencia narrativa de los productos que se van logrando.

El proceso es primero hacer -el producir intuitivo, ágil, diverso, prolífico- antes que pensar o racionalizar desde la teoría (Arendt, 1995). Son aprendizajes que casi no lo parecen, son aprendizajes lúdicos. Después se reflexiona sobre lo hecho buscando las palabras, construyendo relatos, arrojando las palabras sobre los hechos. Se rectifica, se ajusta, y se sigue haciendo disfrutando en la tensión que produce el deseo de seguir haciendo. El actuar, construir, modelar el entorno con los demás y entre los demás antes, incluso, que el dibujar y hacer maquetas, son todas ellas acciones que se sitúan en el ámbito del proyectar autopoiético-innovador. El aprendiz aprende por sí mismo, se hace reflexivo y evoluciona a partir de lo que hace, al observar su propio hacer y en la medida que el lenguaje le permite acotar la experiencia de sus 
actos. La acción le permite ubicarse en el medio, con y entre los demás (Maturana, 2004). Dice Foucault (2010): son las cosas que uno hace, las que le enseñan, le fabrican a uno y no al revés.

En talleres más avanzados se proponen transformaciones de lugares. Se generan acciones que provocan reacciones e interacciones entre los actuantes y los habitantes del lugar. Se produce así un acercamiento antropológico que origina un conocimiento complejo y profundo de la realidad, que desvela lo oculto, lo potencial-latente de esta realidad. Diversos caminos se abren hacia su reinterpretación descubriendo múltiples capas de significación y hacía su reconfiguración. En una pedagogía de estas características, hay un doble postulado: la ruptura y el advenimiento de una situación nueva.

Como señalaba Uberto Eco (1962) (refiriéndose a las reglas de la poética de Aristóteles en el argumento de la tragedia), el argumento ha de procurar que suceda alguna cosa que nos sorprenda, que vaya más allá de lo previsible y que sea lo contrario a la opinión pública aunque para su integración este acontecimiento a pesar de ser ficticio debe ser verosímil. Pablo Bonda (1977) en otro contexto (en torno a lo posmodernol señalaba la destrucción de los códigos, la utilización de forma aberrante de los vocabularios establecidos, un ataque frontal a las convenciones del lenguaje arquitectónico; fisión semántica, crear desde el principio el lenguaje; un cierto arcaísmo (precanónico) en el plano creativo anterior a cualquier consolidación del conocimiento. Analfabetismo que es como noche del lenguaje; analfabetismo que es madurez poética, según Didi Huberman (2009) y que puede tener vastas consecuencias en la educación arquitectónica. La educación, como señalaba H. Read (1982), debería preservar la totalidad orgánica del hombre en forma tal que a medida que pasa de la niñez a la edad adulta, del salvajismo a la civilización, conserve sin embargo esa unidad de conciencia (cuerpo e intelecto) que constituye la única fuente de felicidad individual.

En esta fase de la educación, la comunicación verbal entre profesor y alumno no se centra principalmente en la tarea intelectual, es decir, en el significado sino en la manera de determinar el significado. El objetivo es enseñar las razones por las cuales las formas remiten a sus significados. Eso es enseñar a percibir significados potenciales aunque la mayoría de las veces el aprendiz no pueda verbalizarlos. Es entonces cuando las imágenes adquieren un papel fundamental. Las imágenes no son ni inmediatas, ni fáciles de entender. El estudiante con la ayuda del profesor, cuyo papel se limita sólo a ayudar a que interprete su propia acción registrada con imágenes, su interacción directa con las formas mismas, aprende a construir relatos. "Porque las imágenes no están 'en presente' son capaces de hacer visibles las relaciones de tiempo más complejas que incumben a la memoria en la historia" (Didi-Huberman, 2008). El maestro con habilidad puede desarrollar el talento del aprendiz para construir relatos de una manera creativa.

Los estudiantes insertos dentro de esta estrategia pedagógica aprenden a construir respuestas precanónicas muy subjetivas. Ellos realizan sus intuiciones, construyen sus imágenes mentales. Parten quizá de ideas muy elementales pero descubren en el acto infinidad de valencias abiertas, receptivas de hechos y memoria, capaces de humanizar cualquier la idea. 
Fig.1.

Habitando un paso subterráneo: llevando a cabo acciones cotidianas que transforman en objeto de exposición provocando perplejidad y extrañamiento a los transeúntes.
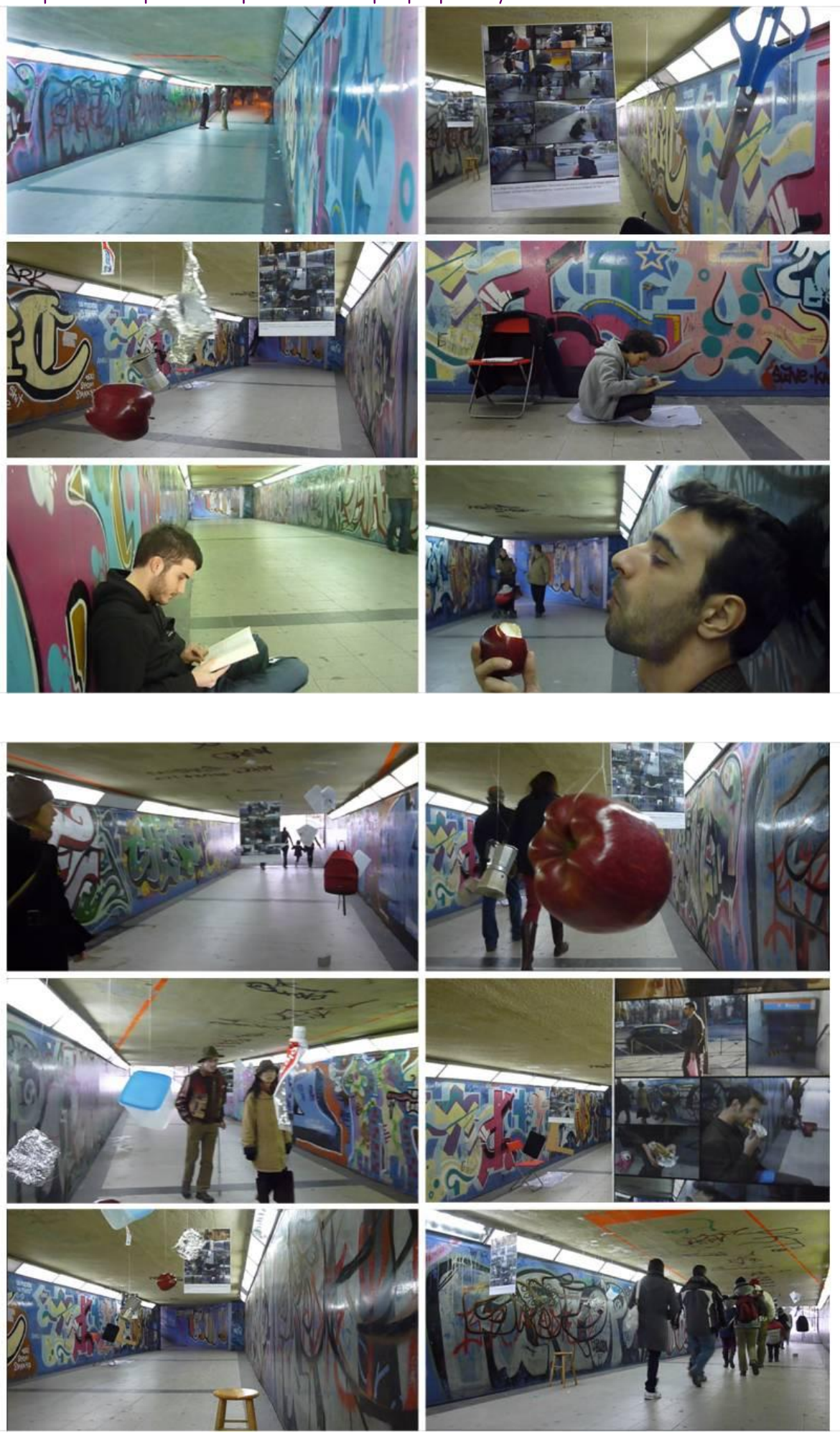
Fig. 2

Sábado noche: acción en la concurrida plaza de la Moncloa, por el conocido 'botellón', en medio del cual estos estudiantes realizan una serie de tareas domésticas cotidianas, descontextualizadas y extrañantes (con la ayuda de unos figurantes) provocando los transeúntes a jugar
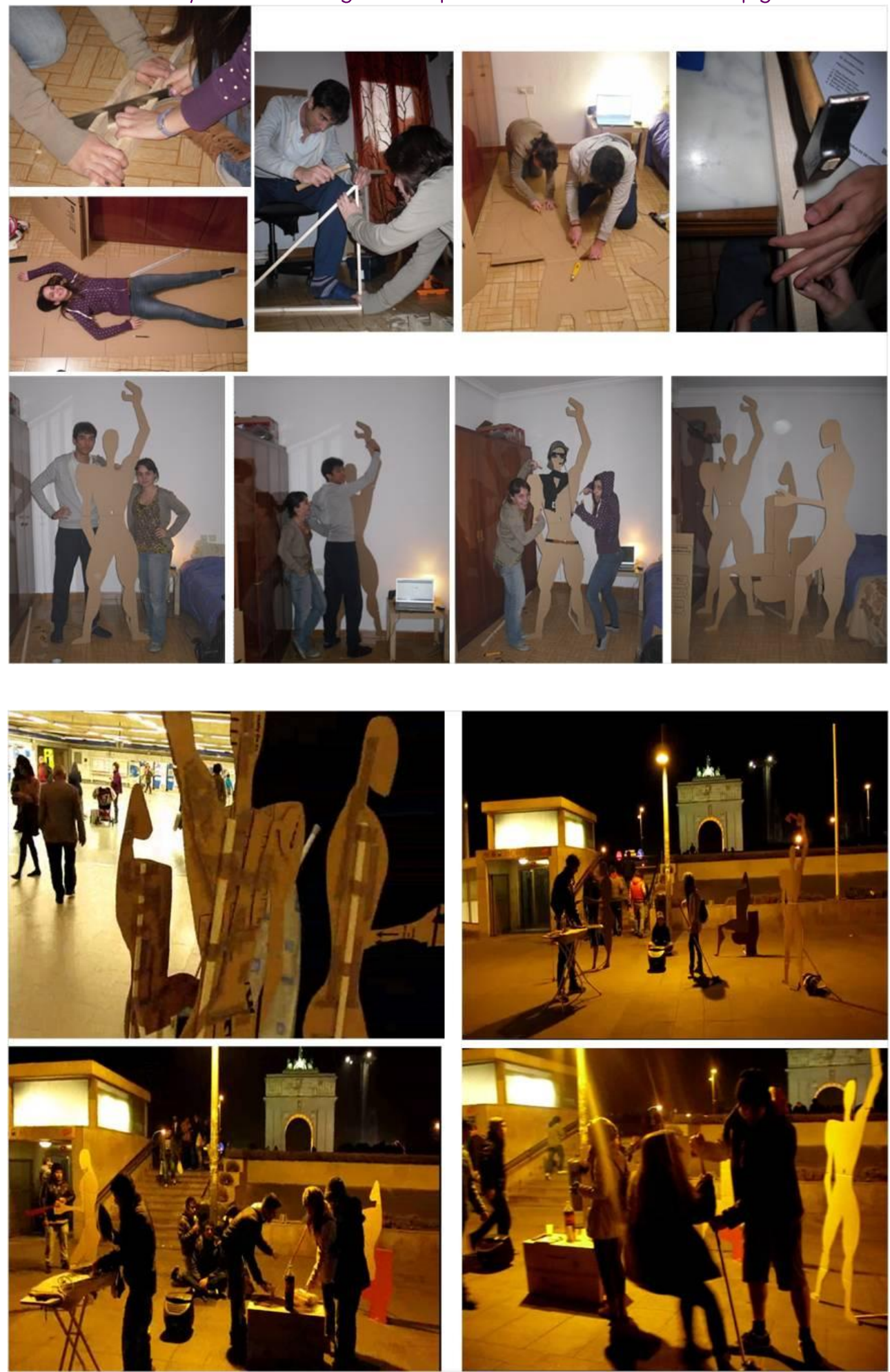

Revista Iberoamericana de Educación / Revista Ibero-americana de Educação (ISSN: 1681-5653) 
Fig.3

A la sombra de aquella farola: acción coincidente con los episodios del 15M. Un grupo de estudiantes dibujó limpiando el suelo de la plaza 'Puerta de sol' de Madrid un enorme árbol como sombra de una farola. Una hermosa metáfora abierta. En la acción se han involucrado los manifestantes en plaza
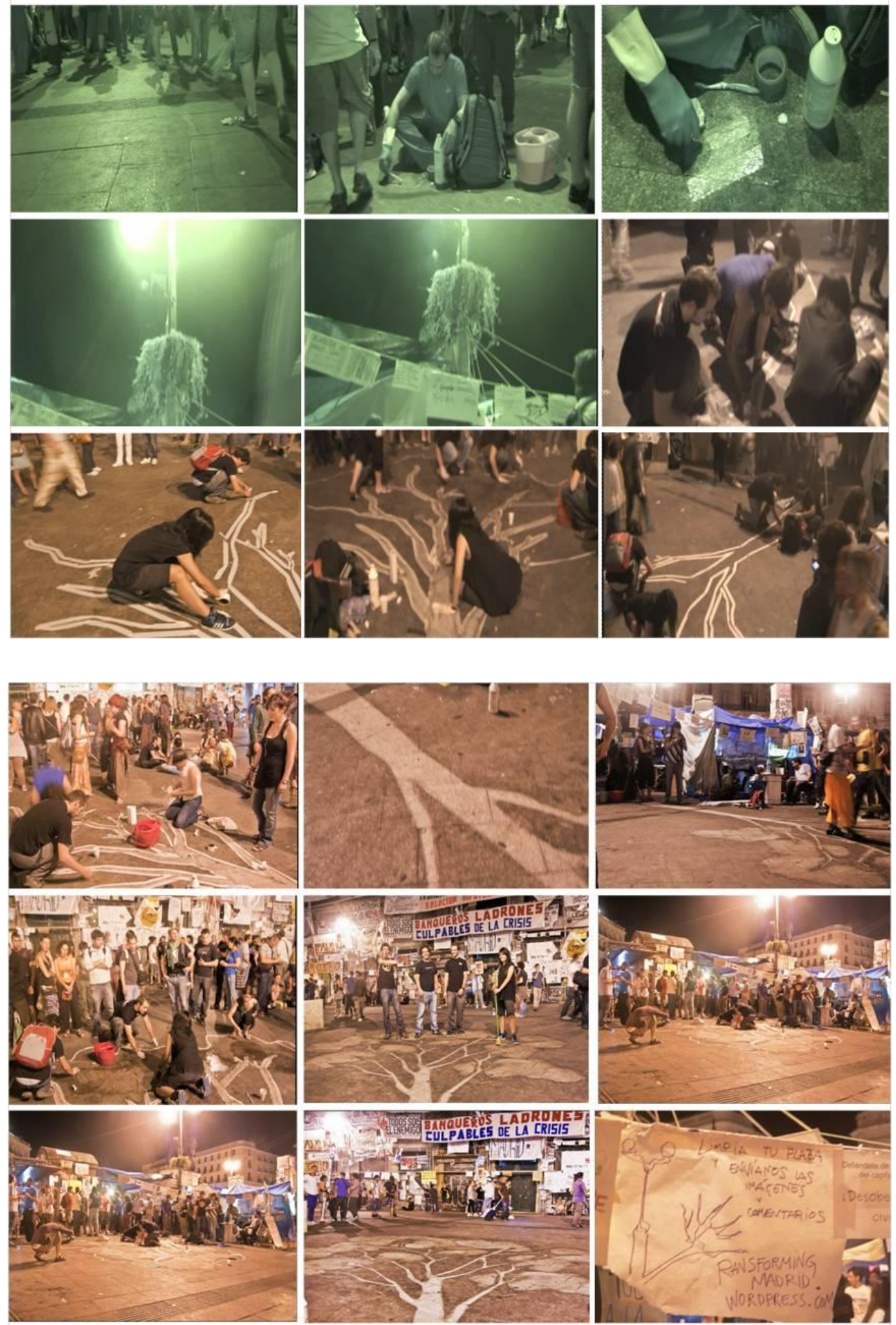

Revista Iberoamericana de Educación / Revista Ibero-americana de Educação (ISSN: 1681-5653) 


\section{Aprender de uno mismo ante el espectáculo de su propia acción}

Una pedagogía del proyectar basada en acciones debe reforzarse con el aprender a recibir sus movimientos y efectos como un espectáculo exterior, como un "espectáculo" sorpresivo", algo que ocurre frente al que lo produce con independencia de sus cálculos pre-determinantes. Así nos hacemos conscientes de nuestras capacidades formantes. La dialéctica entre el acto y el registro es muy importante en este proceso educativo. Registrar y ver uno desde fuera su propia acción como si de un espectáculo se tratase, ayuda a tomar conciencia y provoca una reflexión sobre lo hecho.

Entre el performance como acto creativo y su documentación o registro pueden establecerse diferentes relaciones. El registro (dibujo, fotografía, video) se puede entender como parte de la acción o como prolongación de la propuesta original, en contraposición con las prácticas de la recopilación histórica e informativa propias de la exégesis crítica. Hay también acciones creadas especialmente o rediseñadas en función de su posterior registro. Esta particular relación propone su recepción estética en una tensión que se establece entre los medios de expresión y el acto original donde el medio actúa como un irreductible factor creativo. Una dialéctica que tiene por polos el acto y el registro final del mismo pone en funcionamiento un sistema de relaciones que no pueden ser fijadas de antemano, que se establecen en función del evento. Hay también prácticas que privilegian el registro -fotografía, infografía, video- como soporte y como expresión gráfica antes que la acción registrada. Estas herramientas son imprescindibles en arquitectura. Así el aprendizaje de herramientas se introduce con naturalidad y nunca por separado de los objetivos educativos (Arnheim, 1993). En todo caso, resulta evidente que el registro no agota al acto y que éste no existe independientemente de aquél aunque muchas acciones se proyectan en función del medio de registro elegido, posibilitando una recepción diferente en cada caso (acto, registro), que les permite trascender la instancia de la acción-transformada-en-objeto y su documentación.

La recepción debe entenderse en esos casos como una pugna característica de la confrontación dialéctica entre la génesis y el resultado del acto, donde la complementariedad de los medios se coarta dando lugar a un espacio de indeterminación productivo. Pues, resulta un espacio privilegiado para una relación interactiva (hermenéutica) donde se ponen en marcha las claves de la recepción estética de la obra.

El registro es parte integrante y vital del performance que produce, en este sentido, un doble beneficio educativo. Por un lado, se obtiene una experiencia vital y por otro, una que podríamos llamar metaexperiencia comunicativa en que el registro de la obra se establece como vínculo para aproximarnos aún más a la inmediatez del acto original. La perspectiva mediada del registro posee pues una capacidad extraordinaria de ver más allá de lo que ven los ojos. El aprendiz experimenta, al mismo tiempo, con el potencial expresivo de los diferentes medios y aprende a manejarlos.

No es casual que nuevas expresiones artísticas como el videoarte hayan nacido en el seno de las acciones del grupo Fluxus y entre los performers de los 1970s. El video tiene una extraordinaria capacidad de convertir la instantaneidad del performance en algo que se puede compartir permitiendo además la prolongación temporal de la acción e incluso a través de la edición videográfica, la alteración de los patrones temporales propios del acto performativo. La recepción del mismo y su fruición se enfoca como posibilidad de generar un metadiscurso crítico en relación a la acción y su proceso de ejecución funcionando así como una actualización de la acción original. Ésta posibilística se corresponde perfectamente con un acto proyectivo-arquitectónico, es decir un acto simulativo de transformación del espacio-tiempo. 


\section{Discusión e inercia}

Hemos optado aquí por provocar una discusión y una reflexión sobre ciertos principios en la educación artística -con un potencial de transferencia en las disciplinas proyectuales y muy particularmente en la enseñanza de la arquitectura- antes que mostrar resultados obtenidos y una metodología estructurada y concluyente de nuestro trabajo. En congruencia con lo expuesto, evitamos toda sistematización en nuestro proceder y toda presentación de ejemplaridad de los resultados. Nuestro procedimiento es abierto y siempre en progresión. En los diferentes talleres que ponemos en marcha dentro de diferentes asignaturas, -de contenidos siempre relativos a la actividad proyectual- dependiendo también de la edad de los participantes, se activan mecanismos muy diferentes que nunca repetimos pero sí que nos remiten a otros y nos permiten situarnos ante nuevas perspectivas. Son procesos abiertos y no concluyentes, como ya hemos anticipado, semejantes a los de una educación artística que se retroalimentan continuamente de la realidad y la cotidianidad vinculándose a la antropología del hábitat y la convivencia. Los estudiantes, hemos podido comprobar, se encuentran más cómodos y a la vez más inquietos en este ámbito casi extraacadémico o disidente del mundo académico más seguro, de más autoridad y hasta a veces autoritario, opresivo y hostil para los estudiantes. El grupo de arquitectos y docentes que formamos este grupo de Investigación en Innovación Educativa, fabricamos así agujeros en el entramado educativo universitario donde pueda pasar algo inesperado, que pueda alterar el curso de los acontecimientos y promover algún tipo de consecuencia sorprendente por sus posibles implicaciones en el futuro de nuestra realidad, incluso profesional.

Aprender lúdicamente implica unir el trabajo heurístico y creador al placer; estimular un aumento de la capacidad perceptiva del entorno en todos los niveles, sensible e intelectual, intensificar la capacidad relacional favoreciendo la negociación social y optimizando el trabajo en equipo. Tratamos de infundir la empatía con el otro hasta llegar a hacer desaparecer cualquier tipo de desigualdad y acostumbrar afrontar al carácter incierto de situaciones. Al reconocer y forzar el carácter experimental y ensayístico de los procesos, debemos valorar el fracaso como parte de los mismos y neutralizar el miedo y la idea de fracaso. Eso nos obliga también a abandonar el sistemático empeño de la obtención de plusvalía a través de unos resultados evaluables y mostrables en publicaciones, exposiciones y congresos.

Nuestro objetivo no es la investigación en sí en este campo concreto sino que es la docencia que nos hace investigar y explorar todas las posibilidades que buscan la implicación del alumno en procesos activos. Dentro de un modelo pedagógico flexible, totalmente experimental tratamos de fomentar actitudes hacia el conocimiento ligadas a la transversalidad y la interdisciplinariedad que a través de acciones estratégicas, sientan las bases para el resto de las asignaturas de la carrera.

Lo lúdico, la errancia, el performance, el juego en suma, son buenos enfoques para aprender a proyectar. De hecho, la 'teoría del juego' se aplica hoy al estudio sistemático de los procesos multipersonales de toma de decisiones en situaciones de interdependencia. Los jugadores se influyen recíprocamente. El resultado final para cada uno depende de las acciones de todos y cada uno de ellos. También el profesor es otro jugador a la vez que un entrenador del equipo de juegos.

Parafraseando a Didi Huberman (2008) hablando de la calidad espiritual del baile inventado por Israel Galván, proyectar acciones no procede, obviamente, ni de una doctrina ni de una intención teórica (producir una "metáfora del pensamiento"). Proviene de determinada manera festina lente o del tempo filosófico genuino. Esto es, acentuar el cuerpo, el espacio, y el concepto técnico de la arquitectura como 
configuración del espacio designando el movimiento y la acción como configuradores del espacio vital del ser humano. Así. frente a una arquitectura terminada, estabilizada y estabilizadora de valores -ideológicapretendemos enseñar a proyectar espacios nuevos, dinámicos y fluctuantes al ritmo de la vida humana. Al mismo tiempo, nos abrimos a todas las posibilidades de desarrollar la creatividad como una meta social de la universidad pública.

Las instituciones volcadas en trasmitir el conocimiento -lo que se sabía hasta ahora, encuadrándolo en contenidos que luego se pueden medir en pruebas y exámenes-, pensamos, han de dar paso a espacios para el desarrollo de la creatividad individual y la convivencia. Cuando uno como docente se pone al frente de un grupo de jóvenes con exagerado verbalismo o con la actitud pasiva y rutinaria de quien no tiene nada más que ofrecer, siente en carne propia la frustración y la rabia de saber que ellos están siendo engañados. Las palabras vacías, no calan en los jóvenes. Sólo una verdadera implicación personal y una propuesta respaldada por la praxis llegará al cerebro y al sentimiento de los estudiantes que despertarán del letargo humillante que los acosa y los tiene como muertos. Igual que a los maestros IGardner, 1994, p.88). Son necesarias y urgentes, en este sentido, reformas pedagógicas en la universidad española. Ha de cederse el paso a una educación menos verbalista y academicista, más integral, más dinámica y productiva.

\section{Bibliografía citada}

ACASO, M. NUERE S. (2005): "El curriculum oculto visual: aprender a obedecer a través de la imagen". Arte, Individuo y Sociedad, 17, 205-218.

------ "Pedagogía Tóxica" http://www.slideshare.net/Transversalia/03-que-es-la-pedagoga-toxica [Consulta: ene. 2011]

-------(2009). La educación artística no son manualidades Madrid: Catarata.

AGAMBEN, Giorgio (1998): El hombre sin contenido. Barcelona: Áltera (Orig.1970).

AMAN, A., RAPOSO, J. TRACHANA, A. (2011): "Juego e innovación educativa. las enseñanzas para la iniciación en la creatividad proyectiva". Actas CINAIC 2011 - I Congreso Internacional sobre Aprendizaje, Innovación y Competitividad. Madrid: UPM, 628-635.

ARENDT, Hanna (1995). De la historia a la acción. Barcelona: Paidós.

ARMSTRONG, D. F., Stokoe, W. C. y Wilcox S.E. (1995): Gesture and the Nature of Language. Cambidge: University Press.

ARNHEIM, Rudolf (1993): Consideraciones sobre la educación artîstica. Barcelona: Paidós, Estética.

BAUMANN, Zigmund (2011): Cartas desde el mundo líquido. Barcelona: Paidós (Orig. 2010) .

BONTA, Juan P.ablo(1977): Sistemas de significación en arquitectura. Barcelona: G. Gili.

CONSTANT, N. (1974): "Manifiesto para el catálogo de una exposición sobre para New Babylon en La Haya. http://www.notbored.org/new-babylon.html [Consulta: ene. 2011]

DEBORD, Guy (1957): "Manifiesto Situacionista. Informe sobre la construcción de situaciones y sobre las condiciones de la organización y la acción de la tendencia situacionista internacional. Revista Bifurcaciones:

http://www.bifurcaciones.cl/005/reserva.htm. [Consulta: ene.2011]

DE CERTEAU, Michel (1999): La invención de lo cotidiano, México: Universidad Iberoamericana (Orig.1980).

DELGADO, Manuel (2007): Sociedades movedizas. Barcelona: Anagrama.

DIDI-HUBERMAN, Georges (2008). Cuando las imágenes toman posición. El ojo de la Historia. Madrid: Antonio Machado Libros.

DIDI-HUBERMAN, George (2008): El bailaor de soledades, Valencia: Pre-Textos (Orig.2006).

DIDI-HUBERMAN, George (2009): La imagen superviviente. Madrid: Abada (Orig.2002). 
DUNBAR, R. (2002.69): Grooming, Gossip, and the Evolution of Language. Harvard: University Press (1996).

ECO, Uberto (19842\%). Obra abierta, Madrid: Ariel (Orig. 1962).

GARDNER, Howard (1994. 1). Educación Artística y desarrollo humano. Barcelona: Paidós (Orig. 1943). .

GOFFMAN, E. (1959): The Presentation of the Self in Everyday Life. (Trad. castellano 1959). La presentación de la persona en la vida cotidiana. Buenos Aires: Amorrortu.

HABERMAS, Jürgen (1989): Teoría de la acción comunicativa: Complementos y estudios previos. Madrid: Cátedra (Orig. 1984).

HUIZINGA, J. (1972): Homo Ludens. Emecé Editores España. (Traducción española de Eugenio Imaz, Buenos Aires: Emecé (1968); (Leiden, 1938)

LEFEBVRE, H. (1978): El Derecho a la ciudad, (traducción de J. González-Pueyo; prólogo de Mario Gaviria) Barcelona: Península (Orig.1969).

LÉVI-STRAUSS, C. (1984): El pensamiento salvaje. México: Fondo de Cultura Económica (Orig. 1962).

MATURANA ROMESIN, U., Porksen, B. (2004): Del ser al hacer. Los origenes de la biología del conocer. Santiago de Chile: J.C.Saez Editor,

NANCY, J.-L. (2007): Le Plaisir au dessin, Lyon: Editions Hazan.

NANCY, J.-L. (2003): Corpus. Madrid: Arena Libros (Orig. 1962).

OTEIZA, Jorge (2009, 69): Quosque Tandem. Pamplona: Ed. Pamiela (Orig. 1963).

PERNIOLA, Mario (2002): El arte y su sombra. Madrid: Cátedra (Orig. 2000).

RANCIËRE, Jacques (2002): El maestro ignorante. Barcelona: Laertes (Orig. 1987)

READ, Herbert (1982). Educación por el arte. Barcelona: Paidos (Orig. 1943).

SCHECHNER, R. (2002): Performance Studies: An Introduction, Londres y Nueva York: Routledge.

SCHECHNER, R. (2003): Performance Theory. New York: Routledge (Orig.1977).

SEGUII, J. (2012): Dibujar proyectar XXXVII. Madrid: Instituto Juan de Herrera.

TAYLOR, D. "Hacia una definición de Performance". Traducción de Marcela Fuentes.

http://132.248.35.1/cultura/ponencias/PONPERFORMANCE/Taylor.html [Consulta: ene.2011]

TURNER, V. W. (1988): "The Anthropology of Performance". The Performance Arts Journal Press. New York.

WEISZ, G. (1986): El juego viviente: Indagación sobre las partes ocultas del objeto lúdico, México Siglo: XXI. 